Swarthmore College

Works

$9-1-2018$

\title{
Assessing Sexual Orientation Symptoms In Obsessive- Compulsive Disorder: Development And Validation Of The Sexual Orientation Obsessions And Reactions Test (SORT)
}

M. T. Williams

T. H. W. Ching

G. Tellawi

Jedidiah Siev

Swarthmore College, jsiev1@swarthmore.edu

J. Dowell

See next page for additional authors

Follow this and additional works at: https://works.swarthmore.edu/fac-psychology

Part of the Psychology Commons

Let us know how access to these works benefits you

\section{Recommended Citation}

M. T. Williams, T. H. W. Ching, G. Tellawi, Jedidiah Siev, J. Dowell, V. Schauldt, J. C. Slimowicz, and C. T. Wetterneck. (2018). "Assessing Sexual Orientation Symptoms In Obsessive-Compulsive Disorder: Development And Validation Of The Sexual Orientation Obsessions And Reactions Test (SORT)". Behavior Therapy. Volume 49, Issue 5. 715-729. DOI: 10.1016/j.beth.2017.12.005

https://works.swarthmore.edu/fac-psychology/1077

This work is brought to you for free by Swarthmore College Libraries' Works. It has been accepted for inclusion in Psychology Faculty Works by an authorized administrator of Works. For more information, please contact myworks@swarthmore.edu. 


\section{Authors}

M. T. Williams, T. H. W. Ching, G. Tellawi, Jedidiah Siev, J. Dowell, V. Schauldt, J. C. Slimowicz, and C. T. Wetterneck 


\section{Accepted Manuscript}

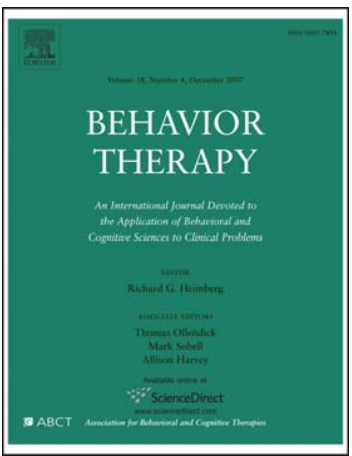

Assessing Sexual Orientation Symptoms in Obsessive-Compulsive Disorder: Development and Validation of the Sexual Orientation Obsessions and Reactions Test (SORT)

Monnica T. Williams, Terence H.W. Ching, Ghazel Tellawi, Jedidiah Siev, Jessica Dowell, Victoria Schauldt, Joseph C. Slimowicz, Chad T. Wetterneck

PII:

S0005-7894(17)30135-1

DOI:

doi: 10.1016/j.beth.2017.12.005

Reference:

BETH 772

To appear in: $\quad$ Behavior Therapy

Received date: 5 July 2017

Accepted date: 9 December 2017

Please cite this article as: Williams, M.T., Ching, T.H.W., Tellawi, G., Siev, J., Dowell, J., Schauldt, V., Slimowicz, J.C. \& Wetterneck, C.T., Assessing Sexual Orientation Symptoms in Obsessive-Compulsive Disorder: Development and Validation of the Sexual Orientation Obsessions and Reactions Test (SORT), Behavior Therapy (2017), doi: 10.1016/j.beth.2017.12.005

This is a PDF file of an unedited manuscript that has been accepted for publication. As a service to our customers we are providing this early version of the manuscript. The manuscript will undergo copyediting, typesetting, and review of the resulting proof before it is published in its final form. Please note that during the production process errors may be discovered which could affect the content, and all legal disclaimers that apply to the journal pertain. 
Assessing Sexual Orientation Symptoms in Obsessive-Compulsive Disorder:

Development and Validation of the Sexual Orientation Obsessions and Reactions Test (SORT)

Monnica T. Williams, ${ }^{1,2}$ Terence H. W. Ching, ${ }^{1}$ Ghazel Tellawi, ${ }^{2,3}$ Jedidiah Siev, ${ }^{4}$ Jessica Dowell, ${ }^{2,4}$ Victoria Schauldt, ${ }^{6}$ Joseph C. Slimowicz, ${ }^{7}$ and Chad T. Wetterneck ${ }^{8}$

${ }^{1}$ Department of Psychological Sciences, University of Connecticut, Storrs, CT

${ }^{2}$ Behavioral Wellness Clinic \& Louisville OCD Clinic, Louisville, KY

${ }^{3}$ Department of Psychological \& Brain Sciences, University of Louisville, Louisville, KY

${ }^{4}$ Department of Psychology, Swarthmore College, Swarthmore, PA

${ }^{5}$ Department of Counseling \& Human Development, University of Louisville, Louisville, KY ${ }^{6}$ College of Psychology, Nova Southeastern University, Fort Lauderdale, FL

${ }^{7}$ VA San Diego Health Care System, San Diego, CA

${ }^{8}$ Rogers Memorial Hospital, Oconomowoc, WI

Correspondence concerning this article should be addressed to: Monnica T. Williams, Ph.D.; Department of Psychological Sciences, University of Connecticut, 406 Babbidge Road, Unit 1020, Storrs, CT 06269; Email: monnica.williams@uconn.edu; Phone: 860-486-0919; Fax: $860-486-2760$ 


\section{ROLE OF FUNDING SOURCES}

This research was funded in part by a grant from the University of Louisville awarded to Ghazel Tellawi.

\section{CONTRIBUTORS}

Monnica T. Williams conceptualized the project and oversaw all aspects of the research. Ghazel Tellawi, Joseph C. Slimowicz, and Victoria Schlaudt helped recruit participants and conduct clinical interviews of OCD patients. Jessica Dowell oversaw data entry and assisted with recruitment of clinical participants. Terence H. W. Ching analyzed the data and drafted the data analysis and results portions of the manuscript. Jedidiah Siev oversaw recruitment, screening, and data collection at one site, and contributed to the writing of the manuscript. Chad T. Wetterneck assisted with the data analysis and conceptualization of the project. All authors contributed to the final version of the manuscript.

\section{ETHICS}

All procedures in this research were approved and performed in compliance with the relevant Institutional Review Board guidelines and the Helsinki Declaration of 1975, as revised in 2000.

\section{ACKNOWLEDGEMENTS}

The authors would like to thank Darlene Davis for development of the data collection instruments and assistance in the collection of student data during the early stages of this project, and Melissa Ellsworth for assistance with data collection from LGBTQ individuals in the community. We also thank Stephanie Budge for assistance in implementing current and sensitive wording for our measures. 


\title{
Assessing Sexual Orientation Symptoms in Obsessive-Compulsive Disorder:
}

\section{Development and Validation of the Sexual Orientation Obsessions and Reactions Test}

(SORT)

\begin{abstract}
Obsessive-compulsive disorder (OCD) includes many symptom presentations, which creates unique diagnostic challenges. Fears surrounding one's sexual orientation are common within OCD (also called SO-OCD), but SO-OCD is consistently misdiagnosed by physicians and psychologists. To address this issue, we describe the development of a self-report measure for assessing SO-OCD to help distinguish OCD from distress caused by a sexual orientation identity crisis. The current manuscript details two studies that established the psychometric properties and clinical utility of this measure. In Study 1, the factor structure, validity, and reliability were examined for the measure's twelve items in a sample of 1,673 university students. The results revealed a two-factor solution for the measure (Factor 1: Transformation Fears, Factor 2: Somatic Checking), and preliminary evidence of validity and reliability. In Study 2, the measure was tested with LGBTQ and heterosexual community samples and clinical samples of individuals with SO-OCD and other types of OCD. The twofactor solution and evidence of validity and reliability were supported in these samples. Cutoff points were established to distinguish between community members and SO-OCD sufferers, as well as between those experiencing SO-OCD and other types of OCD. Limitations and future directions are discussed.
\end{abstract}

Keywords: OCD; sexual orientation; scale development; psychometrics; symptom dimensions 


\section{Introduction}

Obsessive-compulsive disorder (OCD) is a multifaceted disorder with many symptom presentations, which creates unique diagnostic challenges (Sussman, 2003). Due to the heterogeneity of symptoms, there are typically long delays in obtaining a proper diagnosis and effective treatment (Marques et al., 2010; Sussman, 2003). Recent studies of OCD symptom dimensions have generally converged upon four major groupings: contamination/cleaning, symmetry/ordering, doubts about harm/checking, and unacceptable thoughts/mental rituals (Williams, Farris et al., 2011; Williams, Mugno, Franklin, \& Faber, 2013), although some studies have found variations in this pattern (e.g., Katerberg et al., 2010). The unacceptable thoughts/mental rituals category includes obsessions about violence, morality, and sexually inappropriate behavior (Williams, Farris et al., 2014), with compulsions that are often covert (Williams, Crozier, \& Powers, 2011). Concerns about sexual orientation are categorized among fears related to sexual behaviors in OCD.

Sexual orientation concerns in OCD were originally thought to be when a heterosexual person has unwanted thoughts, urges, or mental images about having a different sexual orientation (i.e., same-sex or bisexual); thus, this symptom manifestation was termed 'homosexual OCD' (H-OCD) in initial articles on this topic. This term evolved out of the OCD online self-help community in the early days of the Internet (Williams, 2008). More recent research indicates that sexual orientation concerns are not only present in those who are heterosexual, but that someone who identifies as part of the LGBTQ (lesbian, gay, bisexual, transgender, or queer/questioning) community may have obsessions that they are heterosexual or some other orientation or identity than the one to which they ascribe (e.g., Goldberg, 1984; Williams \& Ching, 2016). Therefore, the term was revised to be more inclusive, and this presentation is now called sexual orientation OCD (SO-OCD; Williams, Slimowicz, Tellawi, \& Wetterneck, 2014; Williams, Wetterneck, Tellawi, \& Duque, 2015). 
Given the stigma that sexual minorities face in society, we believe these obsessions are more likely to develop when stigma is greater. Thus, those identifying as heterosexual are more likely to fear being LGBTQ than LGBTQ individuals fearing being heterosexual, although more research is needed to determine this.

Sexual orientation obsessions are highly distressing to those experiencing them due to the typically ego-dystonic nature of the obsessions and the stigma attached to having a same-sex sexual orientation. In an online study of SO-OCD, Williams, Wetterneck, Tellawi, and Duque (2015) examined 237 heterosexual individuals who reported a prior OCD diagnosis and endorsed distress from sexual orientation-related intrusive thoughts. The majority (91\%) reported high levels of distress related to same sex thoughts, with $21 \%$ reporting a "suicidal" level of distress, $51 \%$ reporting extreme distress, $2 \%$ reporting little distress, $19 \%$ reporting much distress, $5 \%$ reporting moderate distress, and $2 \%$ reporting some distress. Although it is believed that males are more likely to suffer from SO-OCD, females with SO-OCD endorsed higher levels of distress.

The prevalence of SO-OCD is unknown. However, in a large nationwide study, $30 \%$ of those with OCD reported sexual and/or religious obsessions (NCS-R; Ruscio, Stein, Chiu, \& Kessler, 2010). How many individuals experiencing sexual orientation obsessions is not clear as these subgroups were not distinguished from one another. In another study, $25 \%$ of treatment-seeking individuals experienced some form of sexual obsessions during their lives, and this may be an underestimate (Grant et al., 2006). One of the largest studies of clinical OCD symptoms was the DSM-IV Field Trial, which included patients receiving treatment from OCD specialty clinics at seven urban sites ( $n=409$; Foa, Kozak et al., 1995). Of those patients, $17 \%$ reported current or past sexual obsessions as a primary or secondary concern; $8 \%$ had current SO-OCD symptoms and $11.9 \%$ had lifetime SO-OCD (Williams \& Farris, 2011). Using data from the OCD Collaborative Genetics Study $(n=485)$, Pinto et al. 
(2008) found that approximately $10 \%$ of the sample acknowledged past or present obsessions related to unwanted same sex thoughts.

Actual numbers of those with SO-OCD are likely underestimated as SO-OCD is often misunderstood by those afflicted, and are typically misdiagnosed by professionals as a 'sexual identity crisis.' In one vignette study, OCD was misidentified by doctors over half of the time (50.5\%), with misdiagnosing (i.e., underdiagnosis) most frequently in sexual orientation obsessions (84.6\%; Glazier, Swing, \& McGinn, 2015). Glazier, Calixte, Rothschild, and Pinto (2013) conducted another vignette study and found that $38.9 \%$ of psychologists misdiagnosed OCD in general, and the failure rate for a correct diagnosis increased dramatically when the disorder presented with obsessions about homosexuality (77\%). Most recently, McCarty, Guzick, Swan, and McNamara (2017) provided 738 adults in the United States with vignettes describing different OCD symptom dimensions via an online survey. Taboo obsessions (i.e., unacceptable thoughts) were correctly recognized as OCD only $30.9 \%$ of the time (i.e., underdiagnosed), compared with symmetry/incompleteness and contamination concerns ( $84.5 \%$ and $76.1 \%$, respectively). Furthermore, taboo obsessions were viewed in a more stigmatized manner than the other symptom dimensions (e.g., participants wanting more social distance from individuals with taboo obsessions). Considering that SO-OCD is not uncommon but usually unrecognized, there is an important need for a validated measure of SO-OCD concerns. However, there are very few measures to help clinicians distinguish between symptoms of SO-OCD and concerns relevant to a sexual identity crisis.

Williams, Wetterneck, et al. (2015) developed and examined a questionnaire of 70 items tapping into fears of becoming LGBTQ, worries that others may perceive one is LGBTQ, as well as experiences of unwanted same-sex thoughts. Results indicated that these items loaded well onto six components: worries about one's sexual orientation changing; 
same-sex partner desires and experiences; other-sex partner desires and experiences; beliefs in the immorality of same-sex preferences; beliefs in the need to avoid judgments of one's sexual orientation; and sexual orientation shame or dissatisfaction. Additionally, stronger endorsement of these items was related to severe distress and suicidal ideation. However, these items did not constitute a psychometrically validated measure of SO-OCD concerns, as no additional measures were included to establish validity and no cut off scores were determined.

The Sexual Orientation Obsessive-Compulsive Scale (SO-OCS; Melli, Moulding, Gelli, Chiorri, \& Pinto, 2016) is currently the only validated self-report measure of SO-OCD symptoms. The measure includes 14 items that exhibited good psychometric properties in the Italian language, in Central Italy. The measure was created using a sample of Italian, heterosexual non-clinical community participants and OCD patients with and without SOOCD as their primary complaint. The published version of the measure was developed solely for heterosexual individuals who suffer from SO-OCD symptoms. It has not been demonstrated to have the ability to distinguish people with SO-OCD from LGBTQ individuals, nor has it been validated in English. Also, the language used to describe LGBTQ individuals is potentially dated (e.g., using 'homosexual' as a blanket term, instead of specifically referring to individuals as gay, lesbian, etc.; see Wadsworth, Morgan, HaysSkelton, Roemer, \& Suyemoto, 2016). The research presented here establishes a psychometrically sound and validated instrument that can reliably differentiate between SOOCD symptoms versus sexual identity concerns in LGBTQ individuals in English.

\section{Study 1}

In our first study, we aimed to refine and evaluate a self-report measure of SO-OCD symptoms (i.e., the Sexual orientation Obsessions and Reactions Test; SORT) by selecting items from and adding to the survey that was developed and examined by Williams, 
Wetterneck et al. (2015). Specifically, we aimed to obtain a short self-report measure with items that assess for SO-OCD symptoms, thus allowing for quick and efficient administration in clinical and research settings. Additionally, we aimed to improve on significant limitations in the psychometric evaluation process for the SO-OCS. For example, responses from nonclinical LGBTQ individuals, which we believe are vital for differentiation from SO-OCD, were not collected for inclusion in initial factor structure and subsequent construct validity analyses for the SO-OCS. Data on non-SO-OCD-related sexuality concerns such as internalized homophobia and homonegativity were also not collected and examined, despite similarity in content with SO-OCD symptoms, which might in turn explain high rates of misdiagnosis of taboo obsessions including SO-OCD (e.g., Glazier et al., 2015; McCarty et al., 2017). Therefore, the SO-OCS items may conflate SO-OCD concerns with non-SO-OCDrelated sexuality concerns that may be present in LGBTQ and heterosexual individuals. For example, the measure may not distinguish between homophobia and SO-OCD symptoms, even though a past study utilizing clinical observation suggested that the SO-OCD concerns of heterosexual sufferers tend not to be motivated by homophobia (Williams, 2008). Furthermore, although the SO-OCS was able to adequately distinguish people with SO-OCD from those with other forms of OCD, it was developed and validated in the Italian language with Italian participants. Therefore, the purpose of this study is to validate a self-report measure that specifically assesses SO-OCD symptoms in English, and has the ability to distinguish SO-OCD from sexual identity concerns that may be found in LGBTQ individuals. We thus developed our measure for use in the English language with heterosexual and LGBTQ individuals living in the United States.

\section{Method}

\section{Participants and Procedure}

A non-diagnosed, non-referred (i.e., non-clinical) sample of 1,673 self-identified 
heterosexual or LGBTQ students who were enrolled in introductory psychology courses in a large university in Kentucky participated in this study for course credit. These participants were additionally classified into different groups based on whether or not they endorsed the presence of obsessions and/or compulsions on the Wetterneck-Hart OCD Screener (WHOS; Hong, Lee, Wetterneck, \& Hart, 2017), a brief instrument that evaluates OCD symptoms according to DSM-5 criteria (APA, 2013) (see Measures section below). If obsessions and/or compulsions on this measure were endorsed, participants were then required to report whether they were currently experiencing sexual obsessions that involved sexual orientationrelated worries on item 22 of the self-report version of the first edition of the Yale-Brown Obsessive Compulsive Scale (Y-BOCS-SR) Checklist (Goodman et al., 1989; Steketee, Frost, \& Bogart, 1996) (see Measures section below). For the scope of this study, we focused on four different groups: (1) LGBTQ students without OCD symptoms ( $n=180)$; (2) heterosexual students without OCD symptoms $(n=895)$; (3) heterosexual students with SOOCD symptoms ( $n=33)$; (4) heterosexual students with other OCD symptoms $(n=471)$. (These categorizes are based on the WHOS, and group labels are intended to help orient readers to the analyses, but are not intended to suggest that individuals in groups 1 and 2 are completely free of all OCD symptoms. Likewise, sexuality falls on a continuum.) Students who did not fit into one of these groups were excluded from analysis $(n=94)$. Sociodemographic information for each group is reported in Table 1.

Self-identification as either heterosexual or LGBTQ was collected via an open ended item near the beginning of the survey, and then later recoded as a binary variable. Recognizing the limitations of this binary designation, self-identification as either heterosexual or LGBTQ was corroborated with responses corresponding to gay/lesbian and heterosexual identification summaries on the Sell Assessment of Sexual Orientation (Sell, 1996; see Measures section for more information on derivation of these summaries). The 
majority (87.2\%) of LGBTQ students without OCD symptoms identified as "slightly," "moderately," or "very gay/lesbian," while the majority $(66.7 \%-90.2 \%)$ of heterosexual students in the other three groups identified as "not at all gay/lesbian." The majority (82.2\%) of LGBTQ students without OCD symptoms also identified as "slightly," “moderately," or "very heterosexual," which is similar to the way LGBTQ people describe themselves in terms of sexual orientation when given more options, and also likely represents some tendency to endorse responses closer to heteronormative expectations (a style akin to concealment of one's sexuality; Pachankis, 2007). These classifications were cross-checked against the Klein Sexual Orientation Grid (also collected, but not described here; Klein, 1993), with no discrepancies observed.

On the online sign-up page for the study, participants were first provided a brief description that this study was examining sexuality concerns in OCD. After informed consent was obtained, participants were then provided a web link to an online questionnaire containing measures of interest. This study was approved by the university's institutional review board (IRB).

\section{Measures}

Sexual Orientation Obsessions and Reactions Test (SORT) - Preliminary Version. In the present study, we selected from and revised the 70 items examined in the previous study by Williams, Wetterneck, et al. (2015) to generate a refined but preliminary inventory of 49 items that broadly covered the same themes. Importantly, in addition to the goal of being able to reliably and validly assess SO-OCD symptoms, these items were developed for the purpose of being able to distinguish heterosexual individuals with SO-OCD from: (1) heterosexual individuals without OCD; (2) heterosexual individuals with other forms of OCD; and (3) LGBTQ individuals without OCD-related concerns. These items should also distinguish the SO-OCD concerns of heterosexual individuals from the specific non-SO- 
OCD-related sexuality concern of internalized homophobia in LGBTQ individuals without OCD-related symptoms. If possible, these items should also distinguish SO-OCD-related concerns from the specific concern of homonegative attitudes in the entire sample, heterosexual and LGBTQ participants alike. Printed instructions to respondents were: "Select the answer that best corresponds with how you have been feeling over the past month. LGBTQ refers to people who identify as lesbian, gay, bisexual, transgender, and/or queer." Each item can be rated on a five-point scale: 0 (never), 1 (rarely), 2 (sometimes), 3 (often), and 4 (always). Higher numbers correspond to greater endorsement by the respondent. Of these 49 items, nine were intended to be reverse-scored. Thus, higher ratings, after reversescoring, correspond to greater SO-OCD symptom severity.

Wetterneck-Hart OCD Screener (WHOS; Hong et al., 2017). The WHOS is a 4-item self-report screening tool used to assess for the presence of clinically significant symptoms of OCD. The screening questions paraphrase DSM-5 criteria for an OCD diagnosis (APA, 2013). Specifically, these dichotomous yes/no questions inquire about the presence of obsessions, presence of compulsions, distress and functional impairment due to obsessions and/or compulsions, as well as the realization that one's obsessions and/or compulsions are excessive and unreasonable. In this study, the WHOS was used to classify screened students into either of the four aforementioned groups (heterosexual individuals with SO-OCD symptoms, heterosexual individuals without OCD symptoms, heterosexual individuals with symptoms of other forms of OCD, and LGBTQ individuals without OCD symptoms). Participants' endorsements of at least either obsessions or compulsions, as well as the remaining screening questions about distress and insight were required for classification as endorsing OCD symptoms; otherwise, participants were classified as not having OCD-related concerns. The WHOS has been used as a screener in similar studies of OCD (e.g., Wetterneck, Lee, Smith, \& Hart, 2013). 
Yale-Brown Obsessive-Compulsive Scale-First Edition-Self-Report Version (Y-BOCS-

SR) Checklist Item 22 (Goodman, Price, Rasmussen, Mazure, Delgado et al., 1989; Steketee

et al., 1996). The Y-BOCS-SR Checklist provides a comprehensive and valid inventory of items targeting different types of obsessions and compulsions in OCD documented in research and/or observed in clinical practice. Item 22 falls within the sexual obsessions category, and asks about current and/or past experience of sexual orientation-related worries. In the present study, this item was included verbatim as a screening question. For participants who endorsed OCD symptoms on the WHOS, the endorsement of current sexual orientationrelated obsessions on this item was required for classification into the SO-OCD group. Otherwise, these participants were classified into the group with other OCD symptoms.

Sell Assessment of Sexual Orientation (Sell, 1996). The Sell Assessment of Sexual Orientation is an instrument that measures various dimensions of sexual orientation (i.e., attraction, behaviors, and identity) on a continuum, with "homosexuality" on one end and "heterosexuality" on the other. Of the 12 questions rated on different-point scales, six assess sexual attraction, four assess sexual behavior, and two assess sexual orientation identity. Responses to questions in these different dimensions need to be recoded according to instructions described in Sell (1996) to produce sexual orientation summaries for each dimension. In the present study, we created gay/lesbian and heterosexual summaries using just the two sexual orientation identity questions that read "I consider myself..." (1) Not at all gay/lesbian" to (7) Extremely gay/lesbian, and "I consider myself..." (1) "Not at all heterosexual" to (7) "Extremely heterosexual." Each response scale was reduced four categories, "not at all," "slightly," "moderately," or "very" gay/lesbian or heterosexual for simplicity (i.e., responses of 1 being classified as "not at all," responses of 2 and 3 being classified as "slightly," responses of 4 and 5 being classified as "moderately," and responses 
of 6 and 7 being classified as "extremely"). The identity questions corresponded well with the demographic response item assessing self-identification as either LGBTQ or heterosexual.

Reactions to Homosexuality Scale (RHS; Ross \& Rosser, 1996). The RHS is a 26-item measure of internalized homophobia in LGBTQ individuals that includes items developed theoretically and from clinical observations. In this study, the RHS was provided only to participants who self-identified as LGBTQ. This measure assesses four dimensions: (1) public identification as gay or lesbian; (2) perception of stigma associated with being gay or lesbian; (3) social comfort with gay and lesbian individuals; and (4) the moral and religious acceptability of being gay or lesbian. Items are rated on a seven-point scale from 1 (strongly disagree) to 7 (strongly disagree). After reverse-scoring the relevant 12 items, scores are summed to provide a total score, with higher total scores indicating higher internalized homophobia. The RHS demonstrated validity in the original study (Ross \& Rosser, 1996), having exhibited statistically significant (or non-significant) associations in expected directions for each subscale with relationship satisfaction, attraction toward men and women, amount of social time with homosexual individuals, disclosure of sexual orientation, etc. In the original validation study, Ross and Rosser (1996) found acceptable to good internal consistency for each of the four subscales (Cronbach's $\alpha=.62-.85$ ). Furthermore, the four factors were very strongly intercorrelated with each other, justifying the use of a total score, as has been done in other studies (e.g., Dentato, Halkitis, \& Orwat, 2013; Wilkerson, Fuchs, Brady, Jones-Webb, \& Rosser, 2014). In the present study, full-scale internal consistency of the RHS for LGBTQ students without OCD symptoms was acceptable $(\alpha=.72)$.

Modern Homonegativity Scale (MHS; Morrison \& Morrison, 2002). The MHS, evaluating both gay men or lesbian women as the attitudinal target, is a 12-item, unidimensional measure of contemporary negative and prejudiced attitudes toward such individuals. In current version presented to all participants in the present study, we opted to 
modify MHS items to refer to LGBTQ individuals in general as the attitudinal target, on the basis that response data did not vary psychometrically between the original two versions in the original study (Morrison \& Morrison, 2002). Items on the MHS are responded to on a five-point scale from 1 (strongly disagree) to 5 (strongly agree). After reverse-scoring three relevant items, scores are summed to provide a total score, with higher scores indicating more negative attitudes toward LGBTQ individuals. In the original validation study with large student and community samples, the MHS demonstrated good to excellent reliability (Cronbach's $\alpha=.81-.95$ ). It also showed good validity, as attitudes assessed on the MHS shared expected relationships with theoretically linked constructs such as modern racism and modern sexism. In the present study, the MHS showed good internal consistency in the entire sample $(\alpha=.87)$.

\section{Item Selection and Data Analytical Procedure}

There were 1.2\%-1.6\% missing values for each SORT item in each group. Therefore, missing values for each participant were replaced with that participant's adjusted mean item score (mean person imputation). There were no missing values for the other measures. The relevant nine SORT items were reverse-scored prior to analyses.

First, we sought to ensure that SO-OCD symptoms, as assessed with SORT items, differ in an expected manner between groups. To do this, we conducted separate univariate between-groups analyses of variance (ANOVAs) $(\alpha=.05)$, with group membership as the independent variable for each of the 49 SORT items. We selected items that fit the a-priori trend of statistically significantly higher item severity for heterosexual students endorsing SO-OCD symptoms, compared with the other three groups individually, for a total of four groups. Item selection according to this criterion was intended to allow us to construct a preliminary measure on which elevations can be confidently attributed to actual elevations in SO-OCD symptom severity in individuals who endorse such concerns, compared with 
individuals who do not endorse SO-OCD concerns. Twelve items were selected this way (see Table 2 for item wordings $), F \mathrm{~s}(3,1575)=5.00-37.94, M S e s=0.07-1.26, p \mathrm{~s}<.002, \eta_{\mathrm{p}}{ }^{2} \mathrm{~s}=$ $.01-.07 ; p$ s $<.008$ for all pairwise comparisons (after Bonferroni correction) against the other three groups. Notably, none of these 12 items needed to be reverse-scored.

We then conducted a principal component analysis (PCA) with these 12 items to determine the factor structure of the SORT within the entire sample. Specifically, we employed a principal components extraction method with Promax (oblique) rotation, determining the number of factors to extract based on eigenvalues of over 1 and, more importantly, a visual inspection of the scree plot (Costello \& Osborne, 2005) and Horn's (1965) parallel analysis. Items were included on individual components if their loadings were ideally .50 or higher (but not less than .32 ; Costello \& Osborne, 2005) or if there was a strong reason to retain that item due to good fit with the theme of that component and high discrimination between groups based on the ANOVAs. Crossloading was defined as loading .32 on more than one component. Subsequently, we determined reliability of the eventual scale and potential subscales within the entire sample in terms of internal consistency (Cronbach's $\alpha$ ).

Lastly, we conducted a univariate ANOVA $(\alpha=.05)$ to confirm differences in mean SORT total scores between groups, as well as separate Pearson's correlations with RHS (only for LGBTQ students without OCD symptoms) and MHS scores (for each group). This was to test construct validity of the SORT as distinct from the non-SO-OCD-related sexuality concerns of internalized homophobia and homonegative attitudes.

\section{Results}

Principal Component Analysis

Examination of eigenvalues over 1 and visual inspection of the scree plot from the PCA with the selected 12 SORT items converged on a suggested two-component solution, 
which explained $49.8 \%$ of variance. This was further confirmed with Horn's (1965) parallel analysis. The first three eigenvalues were 4.92, 1.06, and 0.88. Despite a drastic reduction in number of items from the earlier published survey of 70 items (Williams, Wetterneck et al., 2015), this value was similar to the $48.4 \%$ of variance explained in that study. Inspection of item loadings suggested that the two components represented: (1) obsessive fears of changing sexual orientation and reassurance (Transformation Fears; 8 items); and (2) compulsive somatic checking and related worries (Somatic Checking; 4 items). Table 2 displays these items with descriptive statistics for the entire sample. Although the majority of items had loaded cleanly and convincingly at or above .50 on their respective component, one did not but was still well above .32 (“2. My sexual fantasies scare me”), as shown in Table 2. Nonetheless, we retained this item because of how well it discriminated the SO-OCD group from other groups, which was in line with the strong fit with the theme of the component, past research evidence, and clinical observations (Williams, Crozier et al., 2011; Williams, Tellawi, Davis, \& Slimowicz, 2015). This allows for a comprehensive assessment of various aspects of sexual orientation obsessions alongside the other items in this component.

\section{Internal Consistency}

Internal consistency of the 12-item SORT for the entire sample was good at $\alpha=.85$.

There was no item for which the Cronbach's $\alpha$-if-item-deleted statistic was much higher than the computed Cronbach's $\alpha$ (cf., Cronbach's $\alpha$-if-item-deleted statistic for "I just want to be like everyone else" $=.86$; see Table 2 ), which provided evidence that all items contributed to internal consistency of the SORT. In terms of the two components, Cronbach's $\alpha$ was .81 for component 1 (Transformation Fears) and .71 component 2 (Somatic Checking), respectively.

\section{Construct Validity}

Mean SORT total scores were significantly different between groups, $F(3,1575)=$ 35.63, $M S e=38.01, p<.001, \eta_{\mathrm{p}}{ }^{2}=.06$. Pairwise comparisons indicated that heterosexual 
students with SO-OCD symptoms indeed endorsed significantly higher SORT scores than the other three groups, $p s<.001$ (see Table 3 for descriptive statistics). Therefore, this finding further corroborated results of our earlier item-level group comparisons.

Zero-order Pearson's correlations were also obtained between the SORT and the RHS for LGBTQ students without OCD, and between the SORT and MHS for each group. The RHS-SORT correlation $(r=.31)$ and MHS-SORT correlations $(r \mathrm{~s}=.15-.35)$ were statistically significant $(p s<.05)$, except for the MHS-SORT correlation for heterosexual students without OCD symptoms $(r=.05, p>.05)$. The significant correlations were, however, small to moderate in magnitude, indicating that the SORT is not merely a proxy measure for internalized homophobic thoughts and homonegative attitudes. Overall, these findings support the SORT as validly assessing SO-OCD symptoms as distinct from the nonSO-OCD-related sexuality concerns of internalized homonegativity in LGBTQ individuals and homonegative attitudes in heterosexual and LGBTQ individuals alike.

\section{Study 2}

In Study 1, we developed a brief measure of SO-OCD symptoms (i.e., the SORT) that evidenced a two-component structure, good internal consistency, and adequate discriminant validity in distinguishing SO-OCD symptoms from general/unspecified and specific non-SO-OCD-related sexuality concerns, in a large non-clinical sample of LGBTQ and heterosexual college students in the United States. In Study 2, we sought to assess the psychometric properties of the SORT within a sample comprising non-clinical LGBTQ and heterosexual community participants, SO-OCD patients, and other-OCD patients. Specifically, we separately explored the factor structure of the SORT in community participants, SO-OCD patients, and other-OCD patients. Additionally, we examined internal consistency, construct validity (i.e., convergent and discriminant validity in regards to non- 
SO-OCD-related sexuality concerns, OCD symptoms, and non-OCD specific symptoms such as worry, anxiety, and depression), as well as criterion validity.

\section{Method}

\section{Participants and Procedure}

A sample $(N=197)$ of 50 LGBTQ community participants without OCD symptoms, 76 heterosexual community participants without OCD symptoms, 33 SO-OCD patients, and 38 patients with other forms of OCD participated in this study. Community participants were recruited from local establishments (e.g., restaurants, gay and lesbian bars, beaches, etc.), and were included if they did not endorse obsessions and compulsions on the WHOS. SO-OCD and other-OCD patients were recruited online and from a private clinic in Kentucky specializing in the treatment of OCD. SO-OCD and other-OCD diagnoses were confirmed directly with the patients' mental health care provider, or determined with comprehensive structured and semi-structured clinical interviews conducted or supervised by a licensed clinical psychologist. Similar to Study 1, self-identification as either heterosexual or LGBTQ was corroborated with homosexual and heterosexual identification summaries on the Sell Assessment of Sexual Orientation. The large majority (84\%) of LGBTQ community participants without OCD symptoms identified as "slightly," "moderately," or "very gay/lesbian," while the large majority $(75.8 \%-90.8 \%)$ of heterosexual individuals in the other three groups identified as "not at all gay/lesbian." Similar to the LGBTQ students in Study 1 , the majority (82\%) of LGBTQ community participants without OCD symptoms also identified as "slightly," "moderately," or "very heterosexual;" this was probably due to the inclusion of bisexual individuals in this group. Lastly, the large majority $(94.7 \%-98.7 \%)$ of heterosexual individuals in the other three groups identified as "slightly," "moderately," or "very heterosexual." Other sociodemographic information for each group is reported in Table 4. 
Procedural details were similar to those in Study 1 (e.g., obtaining informed consent prior to participation, administration of an online questionnaire). This study was approved by the same IRB as Study 1.

Measures

Sexual Orientation Obsessions and Reactions Test (SORT) - Final Version. The SORT is described in Study 1. We used only the 12 items.

Wetterneck-Hart OCD Screener (WHOS; Hong et al., 2013). The WHOS is described in Study 1. In this study, the WHOS was used to screen in community participants who did not endorse OCD symptoms.

Sell Assessment of Sexual Orientation (Sell, 1996). The Sell Assessment of Sexual Orientation is described in Study 1. In this study, we similarly created gay/lesbian and heterosexual identification summaries to corroborate self-identification as either LGBTQ or heterosexual.

Reactions to Homosexuality Scale (RHS; Ross \& Rosser, 1996). The RHS is described in Study 1. The RHS was administered only to LGBTQ community participants without OCD symptoms. Internal consistency of the RHS for this group was acceptable at $\alpha=$ .71 .

Modern Homonegativity Scale (MHS; Morrison \& Morrison, 2002). The MHS is described in Study 1. Internal consistency of the MHS in the entire sample was good at $\alpha=$ .85 .

Yale-Brown Obsessive-Compulsive Scale-Second Edition-Severity Scale (Y-BOCSII-SS; Storch et al., 2010). The Y-BOCS-II-SS consists of 10 items assessing obsessions and compulsions separately (i.e., five items each) on different parameters of severity. Ratings are provided on a six-point scale from 0 to 5 , with higher scores indicating greater severity. The Y-BOCS-II-SS demonstrates high internal consistency (Cronbach's $\alpha=.89$ and .86 , 
respectively), strong direct correlations with OCD measures (e.g., $r=.85$ ), and expectedly moderate indirect associations with measures of worry and depressive symptoms $(r=$ $.20-.35$ ), thus establishing evidence for reliability and validity (Storch et al., 2010; Wu, McGuire, Horng, \& Storch, 2016). In the present study, the Y-BOCS-II-SS was only administered to SO-OCD and other-OCD patients, by a clinician and not online. It demonstrated good to excellent internal consistency in both groups $(\alpha=.93$ and .85 , respectively).

Obsessive-Compulsive Inventory-Revised (OCI-R; Foa, Huppert et al., 2002). The OCI-R is an 18-item self-report measure of distress associated with different OCD symptoms in the past month. Each item is rated on a five-point scale from 0 (not at all disturbed) to 4 (extremely disturbed), with higher scores indicating greater distress. The OCI-R has shown good internal consistency $(\alpha=.85)$ both in the original study and in another study with OCD patients $(\alpha=.83)$ and individuals with other anxiety disorders $(\alpha=.88)$ (Abramowitz \& Deacon, 2006). In the original study, the OCI-R also demonstrated good convergent and discriminant validity with OCD and non-OCD-specific measures in both OCD patients and non-clinical participants (see also Hajcak, Huppert, Simons, \& Foa, 2004; Huppert et al., 2007). In the present study, the OCI-R demonstrated good to excellent internal consistency across groups $(\alpha=.83-.90)$.

\section{Penn State Worry Questionnaire (PSWQ; Meyer, Miller, Metzger, \& Borkovec,} 1990). The PSWQ is a 16-item self-report measure of trait worry, with items rated on a fivepoint scale from 1 (not at all typical of me) to 5 (very typical of me). Higher scores, after reverse-scoring of relevant items, indicate more severe worrying. The PSWQ has shown good psychometric properties. For example, there was excellent internal consistency in the original study $(\alpha=.94)$, and other research has indicated that the PSWQ can effectively distinguish worry from obsessions (e.g., Burns, Keortge, Formea, \& Sternberger, 1996). The PSWQ 
showed acceptable internal consistency across groups in the present study, with Cronbach's $\alpha$ ranging from .70-.77.

Beck Anxiety Inventory (BAI; Beck \& Steer, 1990). The BAI is a widely used, 21item self-report measure of somatic and cognitive symptoms of anxiety in general in the past week. Each item is rated on a four-point scale from 0 (not at all) to 3 (severely), with higher scores indicating greater anxiety. The BAI has shown good psychometric properties (i.e., performing well on in terms of reliability and validity) in numerous studies. The BAI showed excellent internal consistency across groups in the present study $(\alpha=.90-.94)$.

Beck Depression Inventory-Second Edition (BDI-II; Beck, Steer, \& Brown, 1996). The BDI-II is a widely used 21-item self-report measure of depressive symptoms. Items assess the cognitive, affective, and somatic symptoms of depression on a four-point scale from 0 to 3, with higher scores indicating more severe depressive symptoms. The BDI-II has demonstrated excellent psychometric properties in a wide variety of samples (e.g., Sprinkle et al., 2002). The BDI-II showed excellent internal consistency across groups in the present study $(\alpha=.92-.94)$.

\section{Item Selection and Data Analytical Procedure}

There was $1.3 \%-1.6 \%$ missing values for the SORT for each participant in each group. Therefore, missing values for each participant were replaced with that participant's adjusted mean SORT item score (person mean imputation). There were no missing values for the other measures. The relevant PSWQ items were reverse-scored prior to analyses.

First, we conducted a single confirmatory factor analysis (CFA) with the entire sample to replicate the factor structure of the SORT found in Study 1. We then determined reliability of the SORT within each group, as well as full-scale and subscale reliabilities for the entire sample, in terms of internal consistency (Cronbach's $\alpha$ ). 
Next, to confirm group differences in SORT total scores and to assess construct validity of the SORT as distinct from non-SO-OCD-related sexuality concerns, we conducted a univariate ANOVA $(\alpha=.05)$ to confirm differences in mean SORT total scores between groups, as well as separate Pearson's correlations with RHS (only for LGBTQ community participants) and MHS scores (for each group). We additionally conducted an independentgroups $t$-test between SO-OCD patients and LGBTQ community participants without OCD symptoms who scored higher than the group median on internalized homophobia (i.e., > 104 on RHS; $n=22$ ), to determine whether the SORT specifically measures SO-OCD symptoms as distinct from internalized homophobia.

To determine convergent and discriminant validity of the SORT with measures of OCD and non-OCD-specific symptoms in each group, we conducted Pearson's correlations with scores on the Y-BOCS-II-SS (only for SO-OCD and other-OCD patients) and OCI-R, and the PSWQ, BAI, and BDI-II, respectively. These correlations were followed up in each group with the $Z_{\text {contrast }}$ test ( $\alpha=.05$; two-tailed) (Weston \& Rosenthal, 2003) to determine whether convergent associations with OCD symptom measures were significantly larger than discriminant associations with non-OCD-specific symptom measures.

Subsequently, we assessed the criterion validity of the SORT in distinguishing heterosexual patients with a SO-OCD diagnosis from non-clinical LGBTQ and heterosexual community participants, as well as heterosexual patients diagnosed with other forms of OCD. Receiver operating curve (ROC) analyses were conducted, which use the association between sensitivity and specificity to estimate the area under the curve (AUC) for SO-OCD patients with each of the other three groups. A value of 1.0 indicates perfect diagnostic prediction, whereas a value of .50 indicates prediction at chance level. Finally, we obtained the clinical cutoff in each ROC analysis that maximizes sensitivity and specificity. 


\section{Results}

Confirmatory Factor Analysis

A CFA was conducted with the entire sample. The null hypothesis of good fit was rejected, $\chi^{2}(53)=167.42, p<.001$. However, the fit indices demonstrated an adequate fit with the data, GFI $=.89, \mathrm{CFI}=.95, \mathrm{RMSEA}=.08(90 \% \mathrm{CI}=[.06, .10])$. Items loaded adequately onto the Transformation Fears and Somatic Checking components (.58- .90 and $.61-.80$, respectively). See the supplementary information for related figure.

\section{Internal Consistency}

Internal consistency of the SORT was acceptable to excellent across groups (see Table 5). In each group, there was no item for which the Cronbach's $\alpha$-if-item-deleted statistic was more than .01 higher than the computed Cronbach's $\alpha$, evidence that all items contributed to internal consistency of the SORT. Cronbach's $\alpha$ was .94 for the full scale in the whole sample, with $\alpha=.92$ and .81 for the Transformation Fears and Somatic Checking components, respectively.

\section{Construct Validity}

Once again, group differences in SORT total scores were confirmed, and the SORT was able to assess SO-OCD symptoms as distinct from sexuality concerns in heterosexual and LGBTQ individuals. Mean SORT total scores were significantly different between groups, $F(3,193)=24.40, M S e=81.89, p<.001, \eta_{\mathrm{p}}{ }^{2}=.28$. Pairwise comparisons indicated that heterosexual SO-OCD patients reported significantly higher scores than the other three groups, $p s<.001$ (see Table 5 for descriptive statistics). When more specifically comparing SORT scores between SO-OCD patients $(M=21.58, S D=11.72)$ and LGBTQ community participants who scored high on internalized homophobia $(n=22 ; M=5.42, S D=1.16)$, SOOCD patients still scored significantly higher, $t(53)=5.46, p<.001,95 \% \mathrm{CI}=[9.25,19.99]$. This indicated that even among non-clinical LGBTQ individuals high on internalized 
homophobia, SO-OCD symptoms were easily distinguished. Zero-order Pearson's correlations were also obtained between SORT and RHS scores for LGBTQ community participants, and MHS scores for each group. Only the RHS-SORT correlation was statistically significant $(p<.01)$ (see Table 6).

Zero-order Pearson's correlations were also obtained between scores on the SORT and other measures of psychopathology in each group to test convergent and discriminant validity (see Table 6). In community participants, the SORT shared statistically significant relationships with OCD (i.e., OCI-R) and non-OCD-specific measures (i.e., PSWQ, BAI, and BDI-II), $p \mathrm{~s}<.05$, except with the PSWQ in heterosexual community participants, $p>.05$. $Z_{\text {contrast }}$ tests indicated that correlations with the OCI-R were not significantly stronger than correlations with the other measures, $Z \mathrm{~s}=-0.63-0.80, p \mathrm{~s}>.05$, except compared with the correlation with the PSWQ in heterosexual community participants, $Z=3.07, p<.01$. The similar magnitudes of correlations were not unexpected because SO-OCD symptoms were not preponderant in community participants. In SO-OCD and other-OCD patients, the SORT showed statistically significant correlations with OCD measures (Y-BOCS-II-SS and OCI-R), $p s<.001$. There were mixed results with correlations with non-OCD-specific measures (PSWQ, BAI, and BDI-II). Importantly, $Z_{\text {contrast }}$ tests indicated that correlations with the YBOCS-II-SS and OCI-R were significantly stronger than correlations with the other measures, $\mathrm{Zs}=1.97-4.60, \mathrm{ps}<.05$. The two exceptions were the non-significant difference between correlations with OCI-R and PSWQ scores in SO-OCD patients $(Z=1.18, p>.05)$, and between correlations with Y-BOCS-II-SS and BDI-II scores in other-OCD patients $(Z=$ $1.58, p>.05)$. Overall, this was strong evidence of good convergent validity with established measures of OCD symptoms, and good discriminant validity with established non-OCDspecific measures. 


\section{Criterion Validity and Clinical Cutoffs}

Separate ROC analyses were conducted with SO-OCD patients and each of the other groups. In the ROC analysis with SO-OCD patients and LGBTQ community participants without OCD symptoms, the area under the curve (AUC) was $.87, S E=.05,95 \% \mathrm{CI}=[.78$, .96], indicative of good criterion validity in distinguishing patients with a diagnosis of SOOCD from non-clinical LGBTQ community participants. The clinical cutoff of 10 maximized sensitivity (.80) and specificity (.81). Next, in the ROC analysis with SO-OCD patients and heterosexual community participants without OCD symptoms, the AUC was $.85, S E=.04$, $95 \% \mathrm{CI}=[.77, .93]$, similarly indicative of good criterion validity in distinguishing patients with a diagnosis of SO-OCD from non-clinical heterosexual community participants. Again, the clinical cutoff of 10 maximized sensitivity (.80) and specificity (.76). Lastly, in the ROC analysis with SO-OCD patients and other-OCD patients, the obtained AUC was .72, SE= $.06,95 \% \mathrm{CI}=[.60, .84]$, indicative of acceptable criterion validity in distinguishing between heterosexual patients with a diagnosis of SO-OCD from heterosexual patients diagnosed with another form of OCD. The clinical cutoff of 14 maximized sensitivity (.76) and specificity (.64). See the supplementary information for tables of sensitivity and specificity values and figures of ROC curves.

\section{Discussion}

\section{Overview of Psychometric Properties}

The purpose of these studies was to devise a short-self-report measure to identify SOOCD symptoms and distinguish them from sexual orientation concerns unrelated to OCD. Our findings indicate that, with only 12 items, the SORT provides a brief and valid method for assessing SO-OCD within this frequently misdiagnosed disorder.

The analyses supported a two-factor solution to the internal structure of the measure across groups using a principal component's analysis. Due to the content of the items in each 
factor, they were named Transformation Fears and Somatic Checking. These two components are consistent with the construct of OCD that typically includes both obsessions and compulsions (Leonard \& Reimann, 2012; Williams, Farris, et al., 2011).

The SORT has strong psychometric properties, as evidenced by significant correlations with other OCD measures, such as the OCI-R, which was stronger than correlations with other measures of psychopathology, such as the BAI and BDI-II. It also demonstrated strong internal consistency. Furthermore, there was strong concurrent validity, as the measure was able to distinguish individuals with SO-OCD from community members, from those with other types of OCD, and even from LGBTQ individuals who scored high on internalized homophobia.

Notably, the significant correlation between SORT and PSWQ scores in SO-OCD patients instead of other-OCD patients could indicate the people with SO-OCD are more prone to worry. We believe that SO-OCD patients worry about SO-OCD, and therefore, their worry is correlated with the SORT scores. In contrast, other people's worries are not about SO-OCD concerns and therefore their PSWQ scores are less correlated with SORT scores.

\section{Clinical Uses}

Results of the ROC analyses demonstrated that a clinical cutoff score of 10 on the SORT was effective in differentiating between clinical patients with a diagnosis of SO-OCD and individuals without OCD symptoms, including community participants who were either LGBTQ or heterosexual. The score of 14 was most effective when differentiating individuals with SO-OCD from patients with other types of OCD. The cutoff score of 10 is likely to be most useful in a clinical setting, where there is a need to differentiate between SO-OCD and a sexual identity crisis.

The SORT (previously called the SOWACS; Ching \& Williams, in press) has already been used in an undergraduate sample to measure decreases in unwanted sexual orientation 
worries via an experimental intervention. Likewise, the SORT may be appropriate for measuring symptom reduction as a function of treatment for SO-OCD.

\section{Limitations and Suggestions for Future Research}

There were a few limitations in the present study that should be noted. First, there was a group of LGBTQ patients with SO-OCD who were excluded from analyses due to their small numbers $(n=3)$. However, their mean SORT score $(M=25.33, S D=5.69$; range $=$ 19-30) was more similar to that of heterosexual patients with SO-OCD than, for example, LGBTQ community participants without OCD symptoms. Therefore, despite a few researchers and clinicians anecdotally expressing suspicion that SO-OCD does not exist in LGBTQ individuals, this observation provides evidence against that assertion. Unfortunately, there were too few LGBTQ patients with SO-OCD to validate the use of the SORT in this group. More research is needed to quantify and examine empirically this phenomenon in a larger sample of LGBTQ sufferers. Additionally, the binary categories used for sexuality may be limiting and fail to adequately capture differences in scores due to within group differences and stage of sexual identity development. More research with a larger LGBTQ sample will be needed to explore this possibility.

Additionally, there was a lack of ethnic and racial diversity, particularly in the clinical sample. This is largely due to barriers to treatment faced by people of color (Williams, Powers, Yun, \& Foa, 2010). Given this lack of representation, the generalizability of the psychometric properties of the SORT is unknown in ethnic and racial minority individuals. Thus, future research is necessary to examine the psychometric properties of the SORT in diverse groups.

Furthermore, the PCA conducted in LGBTQ and heterosexual community participants indicated that the two-factor solution explained only $51.6 \%$ of variance. This is lower than other OCD related measures, which typically explain over $70 \%$ of variance, including the 
SO-OCS (Abramowitz et al., 2010; Foa, Huppert et al., 2002; Wetterneck, Siev, et al., 2015). However, the variance explained in the SO-OCD and other-OCD patient group was comparable to these previous studies, with $69.6 \%$ of variance explained.

Finally, although the results are promising, clinicians should use caution when attempting to make the differential diagnosis between SO-OCD and sexual orientation issues, and should not use the SORT alone for this purpose. If there is reason to suspect SO-OCD, clinicians should make a referral to an OCD specialist for a more comprehensive evaluation. The sensitivity and specificity of the cut-off scores of the SORT were not perfect, and if, for example, the SORT was used as a screening measure to help identify SO-OCD in the larger population, the clinical cutoff of 10 will result in some false positives, greater in number than the base rate of this phenomenon.

\section{Conclusions}

Despite the limitations of this study, the results suggest that the SORT is the first psychometrically sound self-report measure that can reliably differentiate sexual identity crisis concerns from SO-OCD symptoms. Given the delay in OCD patients receiving accurate diagnoses and adequate treatment, this measure provides a platform for identifying this often incorrectly diagnosed presentation of OCD. Combined with the previously reported rates of suicidal levels of distress associated with sexual orientation obsessions (Williams, Wetterneck et al., 2015), it is critical that such a measure exists to shorten the time between presenting for treatment and receiving an accurate diagnosis. 


\section{References}

Abramowitz, J. S., \& Deacon, B. J. (2006). Psychometric properties and construct validity of the Obsessive-Compulsive Inventory-Revised: Replication and extension with a clinical sample. Journal of Anxiety Disorders, 20, 1016-1035. doi: 10.1016/j.janxdis.2006.03.001

Abramowitz, J. S., Deacon, B. J., Olatunji, B. O., Wheaton, M. G., Berman, N. C., Losardo, D., ... Hale, L. R. (2010). Assessment of obsessive-compulsive symptom dimensions: Development and evaluation of the Dimensional Obsessive-Compulsive Scale. Psychological Assessment, 22, 180-198. doi: 10.1037/a0018260

American Psychiatric Association. (2013). Diagnostic and statistical manual of mental disorders $\left(5^{\text {th }}\right.$ ed.). Washington, DC: Author.

Beck, A. T., \& Steer, R. A. (1990). Manual for the Beck Anxiety Inventory. San Antonio, TX: Psychological Corporation.

Beck, A. T., Steer, R. A., \& Brown, G. K. (1996). Manual for the Beck Depression InventoryII. San Antonio, TX: Psychological Corporation.

Burns, G. L., Keortge, S. G., Formea, G. M., \& Sternberger, L. G. (1996). Revision of the Padua Inventory of obsessive compulsive disorder symptoms: Distinctions between worry, obsessions, and compulsions. Behaviour Research and Therapy, 34, 163-173. doi: 10.1016/0005-7967(95)00035-6

Ching, T. H. W. \& Williams, M. T. (in press). Association splitting of the sexual orientationOCD-relevant semantic network. Cognitive Behaviour Therapy. doi: $10.1080 / 16506073.2017 .1343380$

Costello, A. B., \& Osborne, J. W. (2005). Best practices in exploratory factor analysis: Four recommendations for getting the most from your analysis. Practical Assessment Research \& Evaluation, 10(7). 
Dentato, M. P., Halkitis, P. N., \& Orwat, J. (2013). Minority stress theory: An examination of factors surrounding sexual risk behavior among gay \& bisexual men who use club drugs. Journal of Gay \& Lesbian Social Services, 25, 509-525. doi: $10.1080 / 10538720.2013 .829395$

Foa, E. B., Huppert, J. D., Leiberg, S., Langner, R., Kichic, R., Hajcak, G., \& Salkovskis, P. M. (2002). The Obsessive-Compulsive Inventory: Development and validation of a short version. Psychological Assessment, 14, 485-496. doi: 10.1037/10403590.14.4.485

Foa, E. B., Kozak, M. J., Goodman, W. K., Hollander, E., Jenike, M. A., \& Rasmussen, S. A. (1995). DSM-IV field trial: Obsessive-compulsive disorder. American Journal of Psychiatry, 152, 90-96. doi: 10.1176/ajp.152.1.90

Goldberg, R. L. (1984). Heterosexual panic. American Journal of Psychoanalysis, 44, 209-211. doi: 10.1007/bf01248300

Goodman, W. K., Price, L. H., Rasmussen, S. A., Mazure, C., Delgado, P., Heninger, G. R., \& Charney, D. S. (1989). The Yale-Brown Obsessive Compulsive Scale: Validity. Archives of General Psychiatry, 46, 1012-1016. doi: 10.1037/t57982-000

Glazier, K., Calixte, R., Rothschild, R., \& Pinto, A. (2013). High rates of OCD symptom misidentification by mental health professionals. Annals of Clinical Psychiatry, 25, 201-209.

Glazier, K., Swing, M., \& McGinn, L. (2015). Half of obsessive-compulsive disorder cases misdiagnosed: Vignette-based survey of primary care physicians. Journal of Clinical Psychiatry, 76, e761-e777. doi: 10.4088/jcp.14m09110

Grant, J. E., Pinto, A., Gunnip, M., Mancebo, M. C., Eisen, J. L., \& Rasmussen, S. A. (2006). Sexual obsessions and clinical correlates in adults with obsessive-compulsive disorder. Comprehensive Psychiatry, 47, 325-329. doi: 
10.1016/j.comppsych.2006.01.007

Hajcak, G., Huppert, J. D., Simons, R. F., \& Foa, E. B. (2004). Psychometric properties of the OCI-R in a college sample. Behaviour Research and Therapy, 42, 115-123. doi: 10.1016/j.brat.2003.08.002

Hong, J. H., Lee, E. B., Wetterneck, C.T., \& Hart, J. M. (2017). Need to screen for clinical levels of OCD? Four questions are the key. Bulletin of the Menninger Clinic, 81(3), 247-263. doi: 10.1521/bumc_2017_81_03

Horn, J. (1965). A rationale and test for the number of factors in factor analysis.

Psychometrika, 30, 179-185. doi: 10.1007/bf02289447

Huppert, J. D., Walther, M. R., Hajcak, G., Yadin, E., Foa, E. B., Simpson, H. B., \& Liebowitz, M. R. (2007). The OCI-R: Validation of the subscales in a clinical sample. Journal of Anxiety Disorders, 21, 394-406. doi: 10.1016/j.janxdis.2006.05.006

Katerberg, H., Delucchi, K. L., Stewart, S. E., Lochner, C., Denys, D. A., Stack, D. E., ... Cath, D. C. (2010). Symptom dimensions in OCD: Item-level factor analysis and heritability estimates. Behavior Genetics, 40, 505-517. doi: 10.1007/s10519-0109339-z

Klein, F. (1993). The Bisexual Option. Philadelphia, PA: The Haworth Press.

Leonard, R. C., \& Riemann, B. C. (2012). The co-occurrence of obsessions and compulsions in OCD. The Journal of Obsessive-Compulsive and Related Disorders, 1, 211-215. doi: 10.1016/j.jocrd.2012.06.002

Marques, L., LeBlanc, N. J., Weingarden, H. M., Timpano, K. R., Jenike, M., \& Wilhelm, S. (2010). Barriers to treatment and service utilization in an internet sample of individuals with obsessive-compulsive symptoms. Depression and Anxiety, 27, 470475. doi: 10.1002/da.20694

McCarty, R, J., Guzick, A. G., Swan, L. K., \& McNamara, J. P. H. (2017). Stigma and 
recognition of different types of symptoms in OCD. Journal of Obsessive-Compulsive and Related Disorders, 12, 64-70. doi: 10.1016/j.jocrd.2016.12.006

Melli, G., Moulding, R., Gelli, S., Chiorri, C., \& Pinto, A. (2016). Assessing sexual orientation-related obsessions and compulsions in Italian heterosexual individuals: Development and validation of the Sexual Orientation Obsessive-Compulsive Scale (SO-OCS). Behavior Therapy, 47, 431-443. doi: 10.1016/j.beth.2016.03.004

Meyer, T. J., Miller, M. L., Metzger, R. L., \& Borkovec, T. D. (1990). Development and validation of the Penn State Worry Questionnaire. Behaviour Research and Therapy, 28, 487-495. doi: 10.1016/0005-7967(90)90135-6

Morrison, M.A., \& Morrison, T.G. (2002). Development and validation of a scale measuring modern prejudice toward gay men and lesbian women. Journal of Homosexuality, 43, 15-37. doi: 10.1300/j082v43n02_02

Pachankis, J. E. (2007). The psychological implications of concealing a stigma: A cognitiveaffective-behavioral model. Psychological Bulletin, 133, 328-345. doi: 10.1037/00332909.133.2.328

Pinto, A., Greenberg, B. D., Grados, M. A., Bienvenu, III, O. J., Samuels, J. F., Murphy, D. L., ... Nestadt, G. (2008). Further development of Y-BOCS dimensions in the OCD collaborative genetics study: Symptoms vs. categories. Psychiatry Research, 160, 83-93. doi: 10.1016/j.psychres.2007.07.010

Ross, M. W., \& Rosser, B. R. (1996). Measurement and correlates of internalized homophobia: A factor analytic study. Journal of Clinical Psychology, 52(1), 15-21. doi: 10.1002/(sici)1097-4679(199601)52:1<15::aid-jclp2>3.0.co;2-v

Ruscio, A. M., Stein, D. J., Chiu, W. T., \& Kessler, R. C. (2010). The epidemiology of obsessive-compulsive disorder in the national comorbidity survey replication. Molecular Psychiatry, 15, 53-63. doi: 10.1038/mp.2008.94 
Sell, R. L. (1996). The Sell assessment of sexual orientation: Background and scoring. Journal of Lesbian, Gay and Bisexual Identity, 1, 295-310.

Sprinkle, S. D., Lurie, D., Insko, S. L., Atkinson, G., Jones, G. L., Logan, A. R., \& Bissada, N. N. (2002). Criterion validity, severity cut scores, and test-retest reliability of the Beck Depression Inventory-II in a university counseling center sample. Journal of Counseling Psychology, 49, 381-385. doi: 10.1037//0022-0167.49.3.381

Steketee, G., Frost, R., \& Bogart, K. (1996). The Yale-Brown Obsessive Compulsive Scale: Interview versus self-report. Behaviour Research and Therapy, 34, 675-684. doi: 10.1016/0005-7967(96)00036-8

Storch, E. A., Rasmussen, S. A., Price, L. H., Larson, M. J., Murphy, T. K., \& Goodman, W. K. (2010). Development and psychometric evaluation of the Yale-Brown ObsessiveCompulsive Scale - Second Edition. Psychological Assessment, 22, 223-232. doi: $10.1037 / \mathrm{a} 0018492$

Sussman, N. (2003). Obsessive-compulsive disorder: A commonly missed diagnosis in primary care. Primary Psychiatry, 10, 14.

Wadsworth, L. P., Morgan, L. P., Hayes-Skelton, S. A., Roemer, L., \& Suyemoto, K. L. (2016). Ways to boost your research rigor through increasing your cultural competence (Part 1 of 2). The Behavior Therapist, 39, 76-82.

Wetterneck, C. T., Lee, E. B., Smith, A. H., \& Hart, J. M. (2013). Courage, self-compassion, and values in obsessive-compulsive disorder. Journal of Contextual Behavioral Science, 2, 68-73. doi: 10.1016/j.jcbs.2013.09.002

Wetterneck, C. T., Siev, J., Adams, T. G., Slimowicz, J. C., \& Smith, A. H. (2015). Assessing sexually intrusive thoughts: Parsing unacceptable thoughts on the Dimensional Obsessive-Compulsive Scale. Behavior Therapy, 46, 544-556. doi: 10.1016/j.beth.2015.05.006 
Weston, D., \& Rosenthal, R. (2003). Quantifying construct validity: Two simple measures. Journal of Personality and Social Psychology, 84, 608-618. doi: 10.1037//00223514.84.3.608

Wilkerson, J. M., Fuchs, E. L., Brady, S. S., Jones-Webb, R., \& Rosser, B. R. S. (2014). Correlates of HIV/STI testing and disclosure among HIV-negative collegiate men who have sex with men. Journal of American College Health, 62, 450-460. doi: $10.1080 / 07448481.2014 .917654$

Williams, M. T. (2008). Homosexuality anxiety: A misunderstood form of OCD. In L.V. Sebeki (Ed.), Leading-edge health education issues. (pp. 195-205). Happauge, NY: Nova Science Publishers.

Williams, M. T., \& Ching, T. H. W. (2016). Transgender anxiety, cultural issues, and cannabis in obsessive-compulsive disorder. AACE Clinical Case Reports, 2, e276-e277. doi: 10.4158/ep161356.co

Williams, M. T., Crozier, M., \& Powers, M. (2011). Treatment of sexual-orientation obsessions in obsessive-compulsive disorder using exposure and ritual prevention. Clinical Case Studies, 10, 53-66. doi: 10.1177/1534650110393732

Williams, M. T., \& Farris, S. G. (2011). Sexual orientation obsessions in obsessivecompulsive disorder: Prevalence and correlates. Psychiatry Research, 187, 156-159. doi: 10.1016/j.psychres.2010.10.019

Williams, M. T., Farris, S. G., Turkheimer, E., Franklin, M. E., Simpson, H. B., Liebowitz, M., \& Foa, E. B. (2014). The impact of symptom dimensions on outcomes for exposure and ritual prevention therapy for obsessive-compulsive disorder. Journal of Anxiety Disorders, 28, 553-558. doi: 10.1016/j.janxdis.2014.06.001

Williams, M. T., Farris, S. G., Turkheimer, E., Pinto, A., Ozanick, K., Franklin, ... Foa, E. B. (2011). The myth of the pure obsessional subtype in obsessive-compulsive disorder. 
Depression and Anxiety, 28, 495-500. doi: 10.1002/da.20820

Williams, M. T., Mugno, B., Franklin, M. E., \& Faber, S. (2013). Symptom dimensions in obsessive-compulsive disorder: Phenomenology and treatment with exposure and ritual prevention. Psychopathology, 46, 365-376. doi: 10.1159/000348582

Williams, M. T., Powers, M., Yun, Y. G., \& Foa, E. (2010). Minority participation in randomized controlled trials for obsessive-compulsive disorder. Journal of Anxiety Disorders, 24, 171-177. doi: 10.1016/j.janxdis.2009.11.004

Williams, M. T., Slimowicz, J., Tellawi, G., \& Wetterneck, C. (2014) Sexual orientation symptoms in obsessive compulsive disorder: Assessment and treatment with cognitive behavioral therapy. Directions in Psychiatry, 34, 37-50.

Williams, M. T., Tellawi, G., Davis, D. M., \& Slimowicz, J. C. (2015). Assessment and treatment of sexual orientation obsessions in obsessive-compulsive disorder. Australian Clinical Psychology, 1, 12-18.

Williams, M. T., Wetterneck, C. T., Tellawi, G., \& Duque, G. (2015). Domains of distress among people with sexual orientation obsessions. Archives of Sexual Behavior, 44, 783-789. doi: 10.1007/s10508-014-0421-0

Wu, M. S., McGuire, J. F., Horng, B., \& Storch, E. A. (2016). Further psychometric properties of the Yale-Brown Obsessive Compulsive Scale-Second Edition. Comprehensive Psychiatry, 66, 96-103. doi: 10.1016/j.comppsych.2016.01.007 
Table 1.

Sociodemographic characteristics across student groups in Study 1

\begin{tabular}{|c|c|c|c|c|c|}
\hline Characteristic & Category & $\begin{array}{l}\text { Group 1: } \\
\text { LGBTQ } \\
(n=180)\end{array}$ & $\begin{array}{c}\text { Group 2: } \\
\text { Heterosexual } \\
(n=895)\end{array}$ & $\begin{array}{l}\text { Group 3: } \\
\text { SO-OCD } \\
(n=33)\end{array}$ & $\begin{array}{l}\text { Group 4: } \\
\text { OCD } \\
(n=471)\end{array}$ \\
\hline \multirow{2}{*}{$\begin{array}{l}\text { Gender } \\
\text { (proportion) }\end{array}$} & Male & $28.9 \%$ & 29.3 & $39.4 \%$ & $28.7 \%$ \\
\hline & Female & $71.1 \%$ & 70. & $60.6 \%$ & $71.3 \%$ \\
\hline Age $(M(S D))$ & & $21.53(5.01)$ & $20.82(4.34)$ & $20.21(3.24)$ & $20.72(3.39)$ \\
\hline \multirow{6}{*}{$\begin{array}{l}\text { Race/ethnicity } \\
\text { (proportion) }\end{array}$} & Non-Hispanic White & $76.1 \%$ & $75.2 \%$ & $75.8 \%$ & $80.0 \%$ \\
\hline & Black/African American & 14.49 & $13.8 \%$ & $9.1 \%$ & $10.4 \%$ \\
\hline & Asian/Asian American & $2.2 \%$ & $5.7 \%$ & $9.1 \%$ & $4.9 \%$ \\
\hline & $\begin{array}{l}\text { Native American/Pacific } \\
\text { Islander/Alaskan Native }\end{array}$ & $1.7 \%$ & $0.3 \%$ & $0.0 \%$ & $0.4 \%$ \\
\hline & Hispanic-Latino & $4.5 \%$ & $4.4 \%$ & $6.0 \%$ & $3.5 \%$ \\
\hline & Other & $1.1 \%$ & $0.6 \%$ & $0.0 \%$ & $0.8 \%$ \\
\hline \multirow{2}{*}{$\begin{array}{l}\text { Citizenship } \\
\text { (proportion) }\end{array}$} & United States & $92.8 \%$ & $93.1 \%$ & $97.0 \%$ & $93.6 \%$ \\
\hline & Immigrant & $7.2 \%$ & $6.9 \%$ & $3.0 \%$ & $6.4 \%$ \\
\hline \multirow{3}{*}{$\begin{array}{l}\text { Marital status } \\
\text { (proportion) }\end{array}$} & Single & $88.9 \%$ & $93.9 \%$ & $100.0 \%$ & $95.5 \%$ \\
\hline & Married/partnered & $10.0 \%$ & $5.5 \%$ & $0.0 \%$ & $3.8 \%$ \\
\hline & $\begin{array}{l}\text { Divorced/separated/ } \\
\text { widowed }\end{array}$ & $1.1 \%$ & $0.6 \%$ & $0.0 \%$ & $0.7 \%$ \\
\hline
\end{tabular}

Note. Group 1 = LGBTQ students without OCD symptoms; Group 2 = heterosexual students without OCD symptoms; Group 3 = heterosexual students with SO-OCD symptoms; Group 4 $=$ heterosexual students with other OCD symptoms; $M=$ mean; $S D=$ standard deviation. 
Table 2.

Item descriptive statistics, internal consistency, and item loadings from the principal component analysis of the SORT from Study $1(\mathrm{~N}=1,579)$

\begin{tabular}{|c|c|c|c|c|c|c|}
\hline Item & $M$ & $S D$ & $r_{\text {it }}$ & $\begin{array}{c}\alpha- \\
\text { deleted }\end{array}$ & $\begin{array}{c}\text { Component } \\
1: \mathrm{TF}\end{array}$ & $\begin{array}{c}\text { Component } \\
\text { 2: SC }\end{array}$ \\
\hline $\begin{array}{l}\text { 1. I worry about the thoughts I am } \\
\text { having about people of the same sex. }\end{array}$ & 0.55 & 0.82 & .53 & .84 & .53 & .14 \\
\hline 2. My sexual fantasies scare me. & 0.45 & 0.75 & .56 & .84 & .43 & .29 \\
\hline $\begin{array}{l}\text { 3. I try to reassure myself that I am not } \\
\text { LGBTQ. }\end{array}$ & 0.53 & 1.00 & & .84 & .69 & -.04 \\
\hline $\begin{array}{l}\text { 4. I worry that other people will think } \\
\text { I am LGBTQ. }\end{array}$ & 0.40 & & & .83 & .71 & .05 \\
\hline $\begin{array}{l}\text { 5. I just need to know for sure if I am } \\
\text { straight. }\end{array}$ & 0.35 & & .57 & .83 & .85 & -.15 \\
\hline $\begin{array}{l}\text { 6. I worry that my sexual orientation } \\
\text { may change. }\end{array}$ & & 0.65 & .68 & .83 & .71 & .12 \\
\hline 7. I just want to be like everyone else. & & 1.13 & .33 & .86 & .53 & -.11 \\
\hline $\begin{array}{l}\text { 8. I worry that I will lose control and } \\
\text { become LGBTQ. }\end{array}$ & & 0.54 & .63 & .84 & .73 & .05 \\
\hline $\begin{array}{l}\text { 9. I check myself to see if I am } \\
\text { aroused by sexual images. }\end{array}$ & 0.63 & 0.95 & .54 & .84 & -.08 & .84 \\
\hline $\begin{array}{l}\text { 10. I check myself to see if I am } \\
\text { sexually aroused around other people. }\end{array}$ & 0.48 & 0.81 & .61 & .83 & .03 & .80 \\
\hline $\begin{array}{l}\text { 11. An unwanted sexual thought or } \\
\text { image means I really want to do it. }\end{array}$ & 0.68 & 0.87 & .45 & .84 & -.04 & .68 \\
\hline $\begin{array}{l}\text { 12. I worry a lot if I don't get sexually } \\
\text { aroused when I want to. }\end{array}$ & 0.83 & 1.07 & .47 & .84 & -.00 & .66 \\
\hline
\end{tabular}

Note. SORT $=$ Sexual Orientation Obsessions and Reactions Test $M=$ mean; $S D=$ standard deviation (range for all items was $0-4) ; r_{i t}=$ corrected item-total correlation; $\alpha$-deleted $=$ Cronbach's $\alpha$-if-item-deleted; TF = item loadings in bold on Transformation Fears component; $\mathrm{SC}=$ item loadings in bold on Somatic Checking component. 
Table 3.

Descriptive statistics for the SORT, RHS, and MHS for each student group from Study 1

\begin{tabular}{lcccc}
\hline & SORT & SORT & RHS & MHS \\
& $M(S D)$ & Range & $M(S D)$ & $M(S D)$ \\
\hline $\begin{array}{l}\text { 1. LGBTQ students without OCD } \\
\text { symptoms }(n=180)\end{array}$ & $8.83(7.48)$ & $0-35$ & $95.96(17.55)$ & $26.13(7.98)$ \\
$\begin{array}{l}\text { 2. Heterosexual students without } \\
\text { OCD symptoms }(n=895)\end{array}$ & $5.88(5.83)$ & $0-31$ & - & $29.57(8.77)$ \\
$\begin{array}{l}\text { 3. Heterosexual students with } \\
\text { SO-OCD symptoms }(n=33)\end{array}$ & $15.61(10.93)$ & $2-44$ & - & $30.42(10.12)$ \\
$\begin{array}{l}\text { 4. Heterosexual students with } \\
\text { other OCD symptoms }(n=471)\end{array}$ & $6.34(5.78)$ & $0-33$ & - & $30.00(9.69)$ \\
\hline
\end{tabular}

Note. SORT $=$ Sexual Orientation Obsessions and Reactions Test RHS $=$ Reactions to

Homosexuality Scale; MHS = Modern Homonegativity Scale; $M=$ mean; $S D=$ standard deviation. 
Table 4.

Sociodemographic characteristics across patient and community groups in Study 2

\begin{tabular}{|c|c|c|c|c|c|}
\hline Characteristic & Category & $\begin{array}{l}\text { Group 1: } \\
\text { LGBTQ } \\
n=50\end{array}$ & $\begin{array}{c}\text { Group 2: } \\
\text { Heterosexual } \\
\quad n=76\end{array}$ & $\begin{array}{l}\text { Group 3: } \\
\text { SO-OCD } \\
n=33\end{array}$ & $\begin{array}{l}\text { Group 4: } \\
\text { OCD } \\
n=38\end{array}$ \\
\hline \multirow{2}{*}{$\begin{array}{l}\text { Gender } \\
\text { (proportion) }\end{array}$} & Male & $38.0 \%$ & $34.2 \%$ & $57.6 \%$ & $47.4 \%$ \\
\hline & Female & $62.0 \%$ & $65.8 \%$ & $42.4 \%$ & $52.6 \%$ \\
\hline Age $(M(S D))$ & & $29.80(8.36)$ & $29.22(9.18)$ & $31.36(12.91)$ & $29.92(9.83)$ \\
\hline \multirow{6}{*}{$\begin{array}{l}\text { Race/ethnicity } \\
\text { (proportion) }\end{array}$} & Non-Hispanic White & $90.0 \%$ & $72.4 \%$ & $84.8 \%$ & $84.4 \%$ \\
\hline & Black/African American & $2.0 \%$ & $15.8 \%$ & $9.1 \%$ & $0.0 \%$ \\
\hline & Asian/Asian American & $4.0 \%$ & $3.9 \%$ & $0.0 \%$ & $0.0 \%$ \\
\hline & $\begin{array}{l}\text { Native American/Pacific } \\
\text { Islander/Alaskan Native }\end{array}$ & $0.0 \%$ & $0.0 \%$ & $0.0 \%$ & $0.0 \%$ \\
\hline & Hispanic-Latino & $2.0 \%$ & $6.6 \%$ & $3.1 \%$ & $13.2 \%$ \\
\hline & Other & $2.0 \%$ & $1.3 \%$ & $3.0 \%$ & $2.6 \%$ \\
\hline \multirow{2}{*}{$\begin{array}{l}\text { Citizenship } \\
\text { (proportion) }\end{array}$} & United States & $90.0 \%$ & $88.2 \%$ & $90.9 \%$ & $92.1 \%$ \\
\hline & Immigrant & $10.0 \%$ & $11.8 \%$ & $9.1 \%$ & $7.9 \%$ \\
\hline \multirow{3}{*}{$\begin{array}{l}\text { Marital status } \\
\text { (proportion) }\end{array}$} & Single & $50.0 \%$ & $50.0 \%$ & $75.8 \%$ & $71.1 \%$ \\
\hline & Married/partnered & $44.0 \%$ & $48.7 \%$ & $15.2 \%$ & $26.3 \%$ \\
\hline & $\begin{array}{c}\text { Divorced/separated/ } \\
\text { widowed }\end{array}$ & $6.0 \%$ & $1.3 \%$ & $9.0 \%$ & $2.6 \%$ \\
\hline
\end{tabular}

Note. Group 1 = LGBTQ community participants without OCD symptoms; Group $2=$ heterosexual community participants without OCD symptoms; Group $3=$ heterosexual SOOCD patients; Group 4 = heterosexual patients with other forms of OCD. 
Table 5.

Descriptive statistics for the SORT and other measures for each patient/community group from Study 2

\begin{tabular}{|c|c|c|c|c|c|c|c|c|c|c|}
\hline & & SORT & & RHS & MHS & Y-BOCS- & OCI-R & PSWQ & BAI & BDI-II \\
\hline & $M(S D)$ & Range & $\alpha$ & $M(S D)$ & $M(S D)$ & $M(S D)$ & $M(S D)$ & $M(S D)$ & $M(S D)$ & $M(S D)$ \\
\hline $\begin{array}{l}\text { 1. LGBTQ } \\
\text { community } \\
\text { participants } \\
\text { without OCD } \\
\text { symptoms ( } n= \\
\text { 50) }\end{array}$ & $\begin{array}{c}6.42 \\
(4.93)\end{array}$ & $\begin{array}{l}0-22 \\
\end{array}$ & .75 & $\begin{array}{l}100.36 \\
(14.86)\end{array}$ & $\begin{array}{l}27.14 \\
(6.36)\end{array}$ & & $\begin{array}{l}11.80 \\
(7.62)\end{array}$ & $\begin{array}{c}34.36 \\
(14.52)\end{array}$ & $\begin{array}{l}13.83 \\
(9.37)\end{array}$ & $\begin{array}{l}12.82 \\
(9.10)\end{array}$ \\
\hline $\begin{array}{l}\text { 2. Heterosexual } \\
\text { community } \\
\text { participants } \\
\text { without OCD } \\
\text { symptoms ( } n= \\
76 \text { ) }\end{array}$ & $\begin{array}{c}6.91 \\
(7.60)\end{array}$ & $0-27$ & .89 & - & $\begin{array}{c}31.42 \\
(9.51)\end{array}$ & - & $\begin{array}{c}15.18 \\
(11.26)\end{array}$ & $\begin{array}{c}33.28 \\
(13.82)\end{array}$ & $\begin{array}{c}16.33 \\
(12.47)\end{array}$ & $\begin{array}{c}11.79 \\
(10.06)\end{array}$ \\
\hline $\begin{array}{l}\text { 3. Heterosexual } \\
\text { SO-OCD } \\
\text { patients }(n=33)\end{array}$ & $\begin{array}{c}21.58 \\
(11.72)\end{array}$ & $2-44$ & & & $\begin{array}{c}31.55 \\
(11.03)\end{array}$ & $\begin{array}{l}29.82 \\
(9.72)\end{array}$ & $\begin{array}{c}23.59 \\
(11.27)\end{array}$ & $\begin{array}{c}44.32 \\
(12.15)\end{array}$ & $\begin{array}{c}25.30 \\
(11.49)\end{array}$ & $\begin{array}{c}24.26 \\
(13.28)\end{array}$ \\
\hline $\begin{array}{l}\text { 4. Heterosexual } \\
\text { patients with } \\
\text { other forms of } \\
\text { OCD }(n=38)\end{array}$ & $\begin{array}{c}12.42 \\
(12.62)\end{array}$ & & .90 & - & $\begin{array}{l}29.08 \\
(9.22)\end{array}$ & $\begin{array}{l}33.13 \\
(5.82)\end{array}$ & $\begin{array}{c}24.07 \\
(11.16)\end{array}$ & $\begin{array}{c}50.15 \\
(11.92)\end{array}$ & $\begin{array}{c}22.07 \\
(10.68)\end{array}$ & $\begin{array}{c}24.12 \\
(12.07)\end{array}$ \\
\hline
\end{tabular}

Note. SORT $=$ Sexual Orientation Obsessions and Reactions Test RHS $=$ Reactions to

Homosexuality Scale; MHS = Modern Homonegativity Scale; Y-BOCS-II-SS = Yale-Brown

Obsessive Compulsive Scale-Second Edition-Severity Scale; OCI-R = Obsessive-

Compulsive Inventory-Revised; PSWQ = Penn State Worry Questionnaire; BAI = Beck

Anxiety Inventory; BDI-II = Beck Depression Inventory-Second Edition; $M=$ mean; $S D=$ standard deviation; $\alpha=$ Cronbach's $\alpha$ (internal consistency). 
Table 6.

Correlations between the SORT and relevant measures for each patient/community group from Study 2

\begin{tabular}{|c|c|c|c|c|c|c|c|}
\hline Group & RHS & MHS & $\begin{array}{l}\text { Y-BOCS- } \\
\text { II-SS }\end{array}$ & OCI-R & PSWQ & BAI & BDI-II \\
\hline $\begin{array}{l}\text { 1. LGBTQ } \\
\text { community } \\
\text { participants without } \\
\text { OCD symptoms }\end{array}$ & $.41 * *$ & .15 & - & & $.47 * * *$ & $47 * * *$ & $.49 * * *$ \\
\hline $\begin{array}{l}\text { 2. Heterosexual } \\
\text { community } \\
\text { participants without } \\
\text { OCD symptoms }\end{array}$ & - & .19 & & & -.08 & $.43 * * *$ & $.28^{*}$ \\
\hline $\begin{array}{l}\text { 3. Heterosexual } \\
\text { SO-OCD patients }\end{array}$ & - & -.07 & & $.79 * * *$ & $.65 * * *$ & $.47 * *$ & $.35^{*}$ \\
\hline $\begin{array}{l}\text { 4.Heterosexual } \\
\text { patients with other } \\
\text { forms of OCD }\end{array}$ & - & & $.67 * * *$ & $.72 * * *$ & -.16 & .30 & $.39 *$ \\
\hline
\end{tabular}

Note. SORT $=$ Sexual Orientation Obsessions and Reactions Test; RHS = Reactions to Homosexuality Scale; MHS = Modern Homonegativity Scale; Y-BOCS-II-SS = Yale-Brown Obsessive Compulsive Scale-Second Edition-Severity Scale; OCI-R = ObsessiveCompulsive Inventory-Revised; PSWQ = Penn State Worry Questionnaire; BAI = Beck Anxiety Inventory; BDI-II = Beck Depression Inventory-Second Edition; $M=$ mean; $S D=$ standard deviation; The top column represents the zero-order Pearson's correlation between the SORT and measure listed to the right. ${ }^{*} p<.05 ; * * p<.01 ; * * * p<.001$ (two-tailed). 


\section{HIGHLIGHTS}

- We developed a brief self-report measure for assessing sexual orientation-OCD symptoms.

- A two-factor structure was found across student, community, and OCD samples.

- There was evidence of good reliability and convergent and discriminant validity.

- The measure can also distinguish SO-OCD from unrelated sexual orientation concerns.

- A cutoff of 10 separates SO-OCD patients from LGBTQ individuals without OCD. 